\title{
A Arte de Doar e Compartilhar Vida: reflexão sobre doação de órgãos e tecidos humanos por meio de exposição de arte
}

The Art of Donating and Sharing Life: reflections upon the organ and humantissue donation by means of an art exhibition

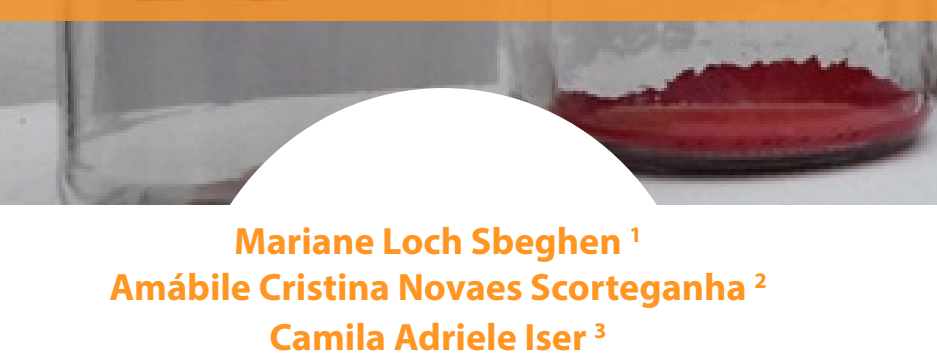

RESUMO

A exposição A Arte de Doar e Compartilhar Vida buscou sensibilizar para a conscientização da doação de órgãos e tecidos, durante evento de pesquisa e extensão da Universidade de Passo Fundo (UPF), e avaliar de maneira qualitativa a percepção dos visitantes da roda de conversa sobre a temática decorrente da exposição. A mostra de arte foi composta por trabalhos realizados por alunos e ex-alunos do curso de Artes Visuais, da UPF, durante os anos de 2013 e 2016, na linguagem visual de gravura organizada de maneira a compor uma instalação. Visando a oportunidade de troca de experiências acerca da temática e o acesso à informação, a exposição contou com a visita de acadêmicos e extensionistas da Universidade, além da Comissão Intra-hospitalar de Doação de Órgãos e Tecidos para Transplante (CIHDOTT) do Hospital São Vicente de Paulo (HSVP) da cidade de Passo Fundo.Observou-se que a exposição dos objetos de arte foi fundamental para promover a reflexão e a sensibilização decorrente da temática abordada na III Semana do Conhecimento, pois, durante a roda de conversa, houve a contribuição da mostra para a memória visual dos participantes.

Palavras-chave: Artes visuais. Doação de órgãos e tecidos. Gravura. Instalação.

\footnotetext{
${ }^{1}$ Mestra em História (UPF), Coordenadora do curso de Artes Visuais (FAC/UPF) e Orientadora do projeto de extensão Comunidades Sustentáveis. E-mail: aneloch @upf.br

${ }^{2}$ Pós-graduanda do curso de Especialização em Arteterapia (UPF). E-mail: amabile.cns@gmail.com

${ }^{3}$ Pós-graduanda do curso de Especialização em Arteterapia (UPF). E-mail: camilaaiser@ gmail.com
} 
The exhibition A Arte de Doar e Compartilhar Vida(The Art of Donating and Sharing Life) sought to raise the awareness of organs and tissue donation, during an event of research and extension of the Universidade de Passo Fundo (UPF) (University of Passo Fundo). It also intended to assess, with a qualitative approach, the perception of the visitors of the conversation circle concerning the theme of the exhibition. The art showing was composed of projects done by students and ex-students of the course of Visual Arts from UPF, during the years of 2013 and 2016, utilizing the technique of engraving. They were organized as to compose an installation in the exhibition space. Aiming to provide an opportunity for sharing experiences concerning the theme of organs and tissues donation as well as the access of information, the exhibition had the visit of students of the course and people from the university's extension program. It also counted with the Comissão Intra-hospitalar de Doação de Órgãos e Tecidos para Transplante (CIHDOTT) (Intra-hospital Commission for Organs and Tissues Donation and Transplant) of the Hospital São Vicente de Paulo (HSVP) (São Vicente de Paulo Hospital) from the city of Passo Fundo. It was observedthat the exhibition of the objects of art was fundamental to promote the reflection arising from thetheme discussed in the III Semana do Conhecimento (Week of Knowledge), because,throughout the conversation circle, there was the support of the exhibition for the participants' visual memory.

Key-words: Visual arts. Organs and tissues donation. Engraving. Installation.

\section{INTRODUÇÃO}

A doação de órgãos e tecidos humanos tem aberto discussões em várias comunidades. A falta de esclarecimento, a ausência de programas permanentes voltados para a conscientização da população e o incentivo à captação de órgãos contribuem para alimentar dúvidas e preconceitos (MORAIS; MORAIS, 2012).

Conforme o Registro Brasileiro de Transplantes, da Associação de Transplantes de Órgãos (ABTO, 2016), referente aos meses de janeiro a setembro de 2016, o número de transplantes e doações não cresceu conforme o esperado. Na fila de espera para transplante, até a data de publicação do RBT, estavam 32.712 pacientes ativos, esperando órgãos, como rim, fígado, coração, pulmão, pâncreas e córnea. Este número só tem aumentado conforme a ABTO, responsável da divulgação dos dados 
brasileiros. O grande causador pela lista de espera não diminuir é o fato de que hoje, no país, há necessidade do consentimento familiar em casos de morte encefálica do paciente. $\mathrm{O}$ número de recusa até setembro chegou a $44 \%$, ou seja, 1.965 possíveis doadores descartados, muitas vezes por falta ou falha de informação acerca da doação de órgãos e tecidos.

Com este tema, percebe-se que a atividade educativa é uma im-portante oportunidade de troca de experiências acerca da temática de doação, permitindo o acesso à informação. Os espaços expositivos de arte são capazes de despertar a consciência crítica, cumprido com seu papel social, pois, por meio da arte, é possível perceber o mundo, e, a partir disso, analisar a realidade, e, assim, modificá-la (BARBOSA, 2009).

Em vista do exposto, objetivou-se com a exposição "A Arte de Doar e Compartilhar Vida" sensibilizar para a conscientização da doação de órgãos e tecidos, durante o evento da III Semana do Conhecimento, e avaliar de maneira qualitativa a percepção dos visitantes da oficina decorrente da exposição, sobre esse tema.

\section{METODOLOGIA}

A exposição A Arte de Doar e Compartilhar Vida foi realizada duran-te evento de extensão na Universidade de Passo Fundo (UPF), Passo Fundo, RS, BRA. O evento em questão foi a III Semana do Conhecimen-to que ocorreu entre os dias 3 e 7 de outubro de 2016, no Campus do Município de Passo Fundo.A mostra de arte foi composta por trabalhos realizados por alunos e ex-alunos do curso de Artes Visuais, da UPF, durante os anos de 2013 e 2016, apresentando as linguagens visuais de gravura e estêncil que foram organizadas de maneira a compor uma instalação (Fotografia 1) no espaço escolhido para sua apresentação.Instalação, em Artes Visuais, trata-se de uma proposta queprocura construir um ambiente ou uma cena em que os objetos e as estruturas que a compõem interagem com o espaço em que está e também com o corpo e o ponto de vista do observador. Geralmente é projetada para um espaço específico e, às vezes, apenas para um curto período de tempo (KLEIN; KLEIN, 2012). Nesta forma de exposição de arte, o apreciador da obra necessita percorrer a instalação para poder contemplá-la, ou mesmo interagir com ela. A Instalação, enquanto poética artística, per-mite grande possibilidade de suportes, e, em sua realização, pode inte-grar diversos materiais e técnicas. 


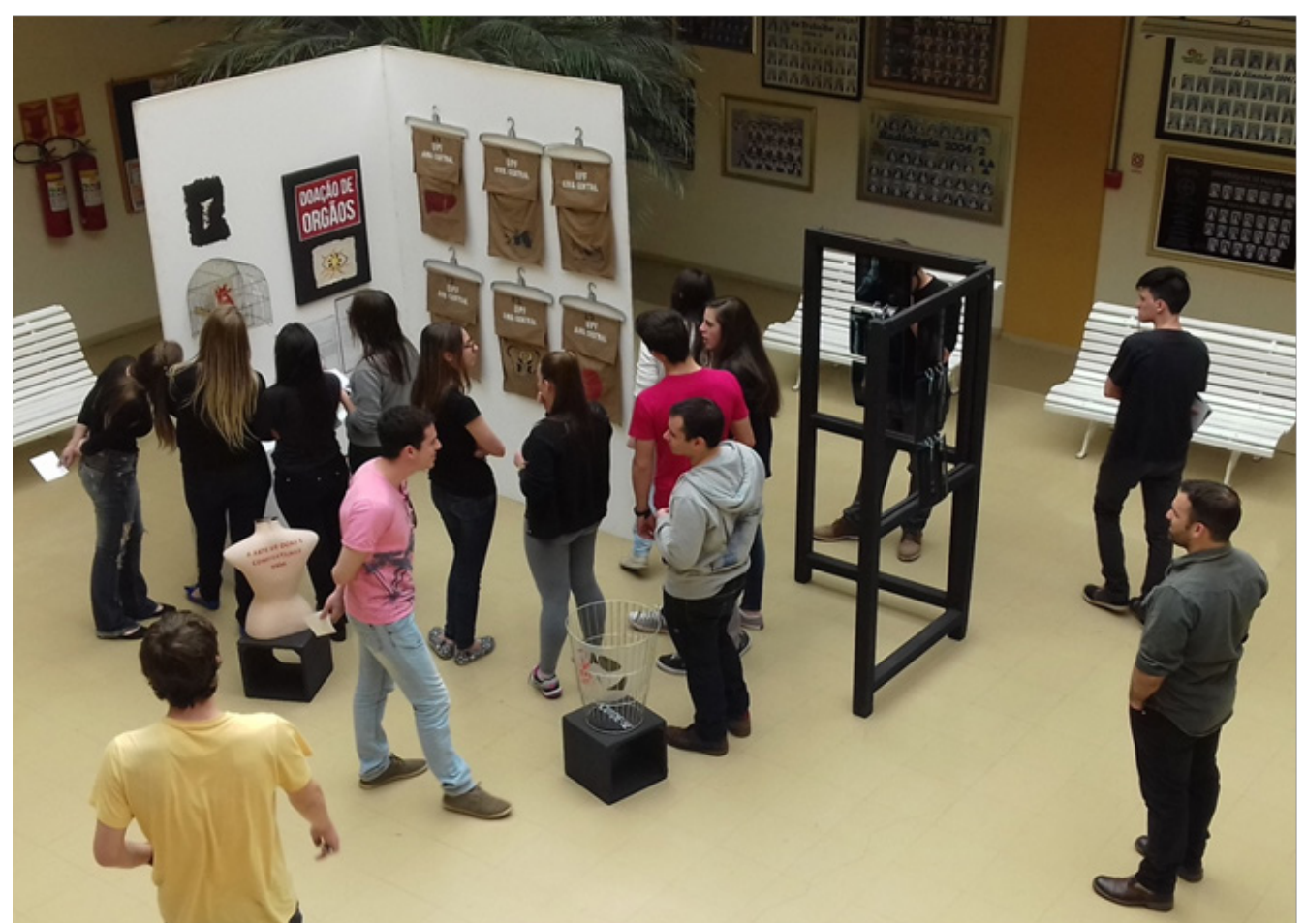

Fonte: SBEGHEN; SCORTEGANHA; ISER, 2016.

Em relação às técnicas de gravura e estêncil, ambas permitem a reprodução em série da mesma imagem. Gravura é o termo que designa, em geral, desenhos feitos em superfícies duras, tais como madeira (xilogravura), pedra (litografia) e metal (calcogravura), com base em incisões, corrosões e talhos realizados com instrumentos e materiais específicos. Já o estêncil, alternativa da técnica de serigrafia, possui como matriz pranchas recortadas com a imagem ou escrita que se deseja reproduzir (STRICKLAND; BOSWELL, 2014).

Os materiais utilizados na confecção dos objetos relacionam-se com o tema da exposição, sendo materiais que iriam para descarte e que foram reaproveitados e ressignificados. Por meio do reaproveitamento de materiais, a exposição estabelece diálogo com o tema da doação de órgãos e tecidos de maneira subjetiva. Para isso, utilizaram-se vidros de conserva, papel reciclado, gaiola, lixeira de arame, manequim, cabides com antigas sacolas de tecido do antigo ambulatório da UPF e radiografias.

A proposta da exposição ocorreu através de diálogo da Coordenadora do Curso de Artes Visuais, da Universidade de Passo Fundo, e curadora da exposição, com a Coordenação do projeto Com Saúde, da Universidade de Passo Fundo, e com a Comissão Intra-Hospitalar de Doação de Órgãos e Tecidos para Transplante (CIHDOTT) do Hospital São Vicente de Paulo (HSVP), com o intuito de sensibilizar através da arte a importância da doação de órgãos e tecidos, e a divulgação da Campanha Permanente de Doação de Órgãos e Tecidos - Doe Órgãos: uma corrente pela vida do HSVP.
Fotografia 1

Participantes durante visita à exposição $A$ Arte de Doar e Compartilhar. Vida. 
Visando a oportunidade de troca de experiências acerca da temática de doação de órgãos e tecidos e permitindo o acesso à informação, a exposição contou com a visita de acadêmicos e extensionistas dos cursos de Medicina, Serviço Social, Psicologia, Jornalismo e Artes Visuais, além da Comissão Intra-hospitalar de Doação de Órgãos e Tecidos para Transplante (CIHDOTT) do Hospital São Vicente de Paulo (HSVP).

Os participantes reuniram-se em uma sala onde receberam a orientação de levar um pedaço de papel e caneta para atribuir títulos aos trabalhos expostos. Após a visita na exposição, os participantes retornaram à sala para um momento de sensibilização para a partilha das impressões sobre a mostra, exposição dos títulos atribuídos a cada trabalho e conversa sobre sua temática.

Ao final das falas dos participantes, houve a contribuição de relatos de sujeitos transplantados que se revelaram para o grupo compartilhando suas vivências durante a espera do transplante e posterior a ele, o que causou emoção nos presentes.

Fotografia 2 Manequim com o título da exposição gravado com a técnica de estêncil.

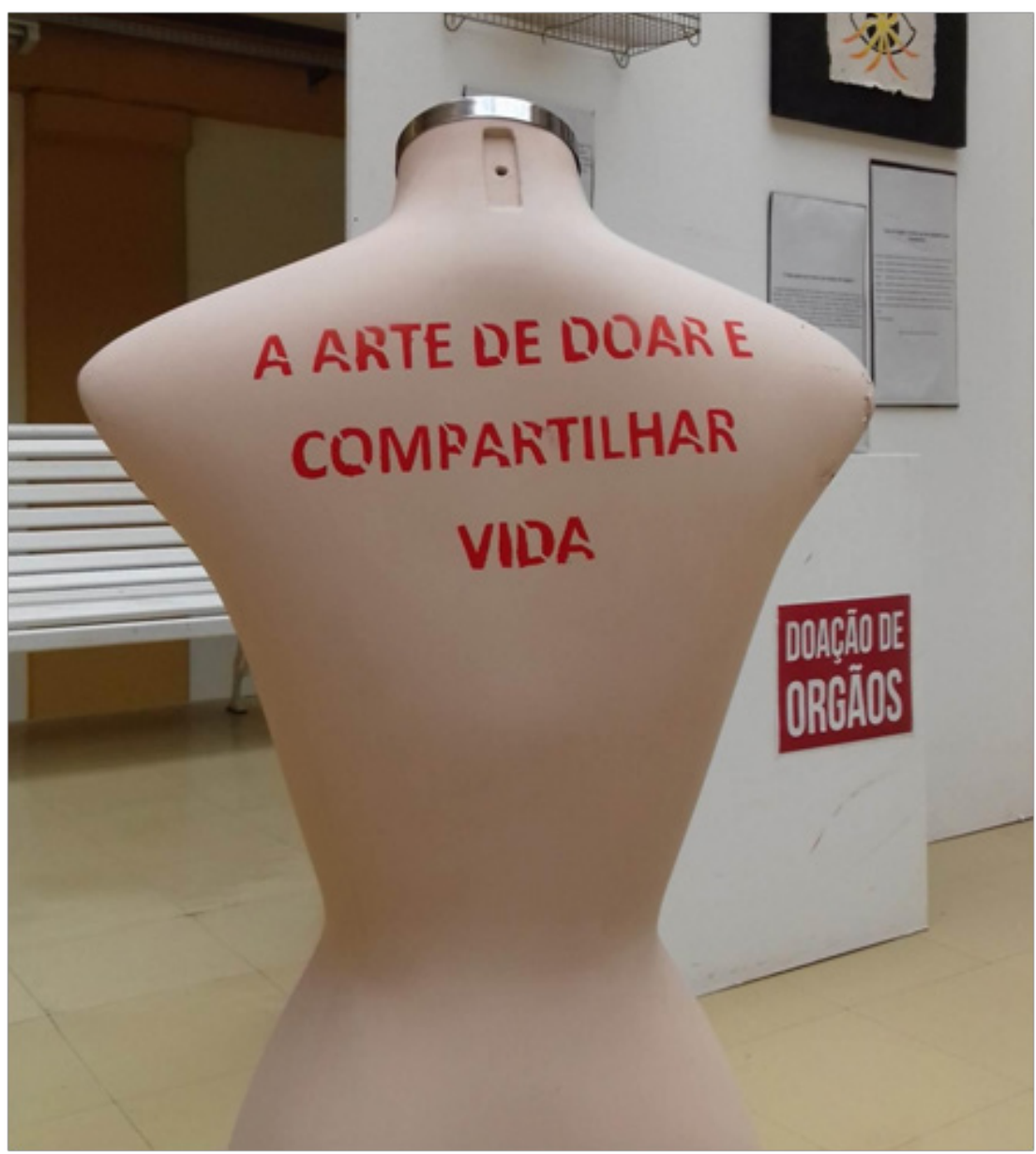

Fonte: SBEGHEN; SCORTEGANHA; ISER, 2016. 


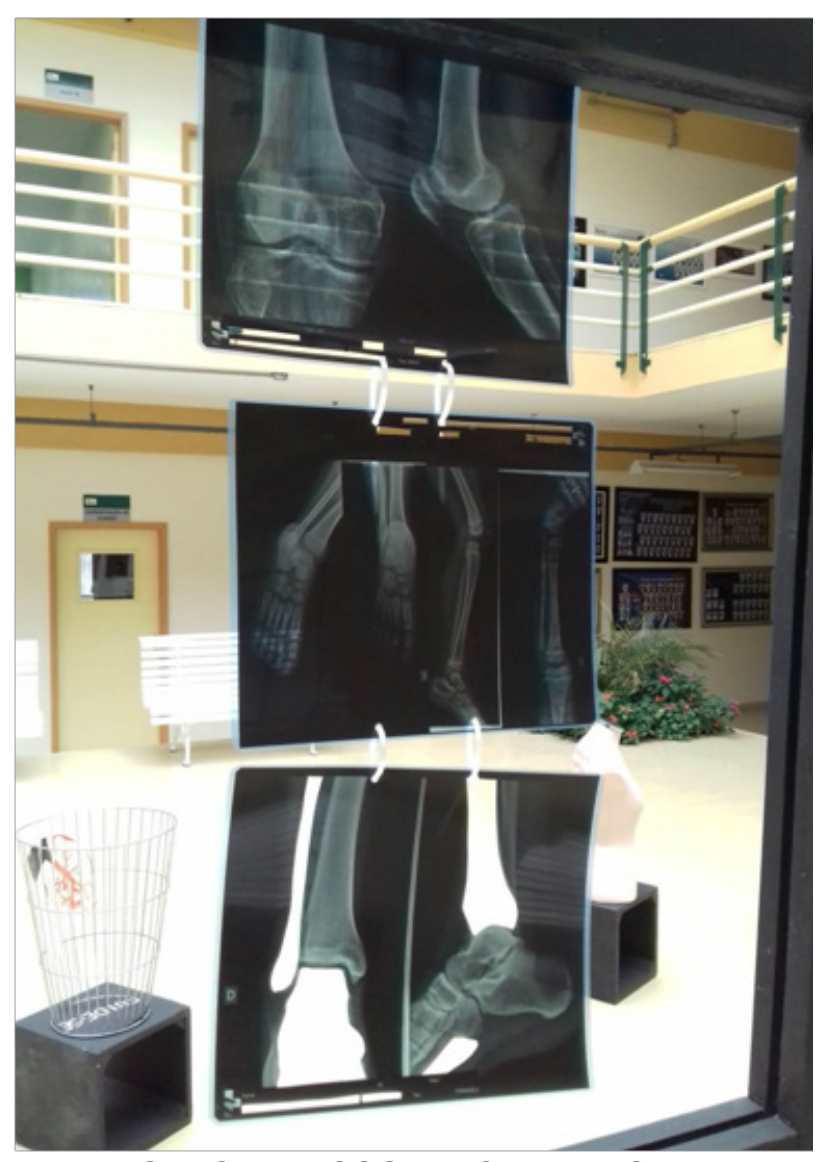

Fonte: SBEGHEN; SCORTEGANHA; ISER, 2016.

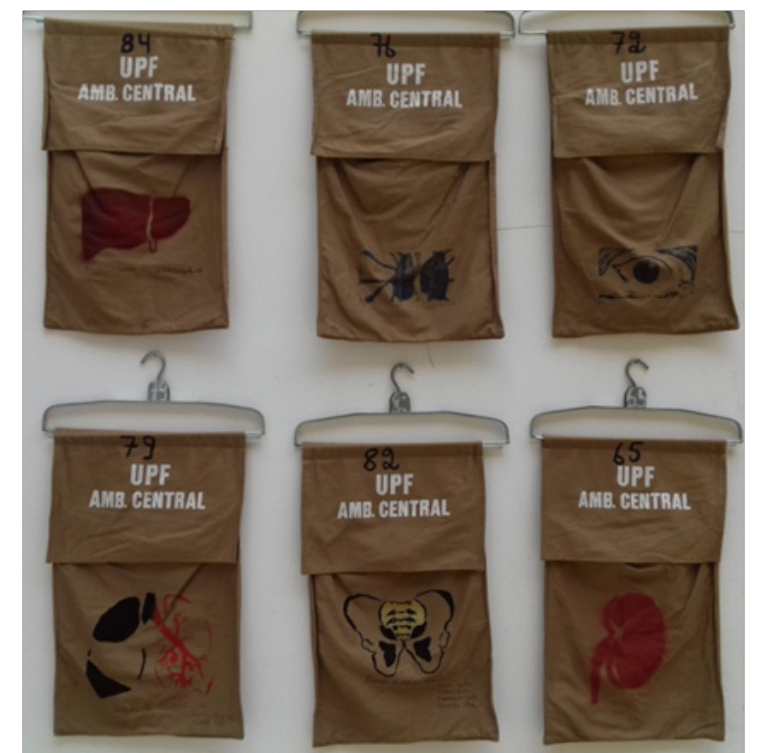

Fonte: SBEGHEN; SCORTEGANHA; ISER, 2016.
Fotografia 3

Trabalho com reaproveitamento de radiografias intitulado Na Transparência do Corpo, a Silhueta do Destino.
Fotografia 4

Conjunto de bolsas de algodão do antigo ambulatório central da UPF compondo o trabalho de título Cabide de vidas. 
167 - SBEGHEN, M. L. et al.

Fotografia 5

Cesto de metal com representação de pulmão cujo trabalho recebeu o título de Não se lixe. Doe!

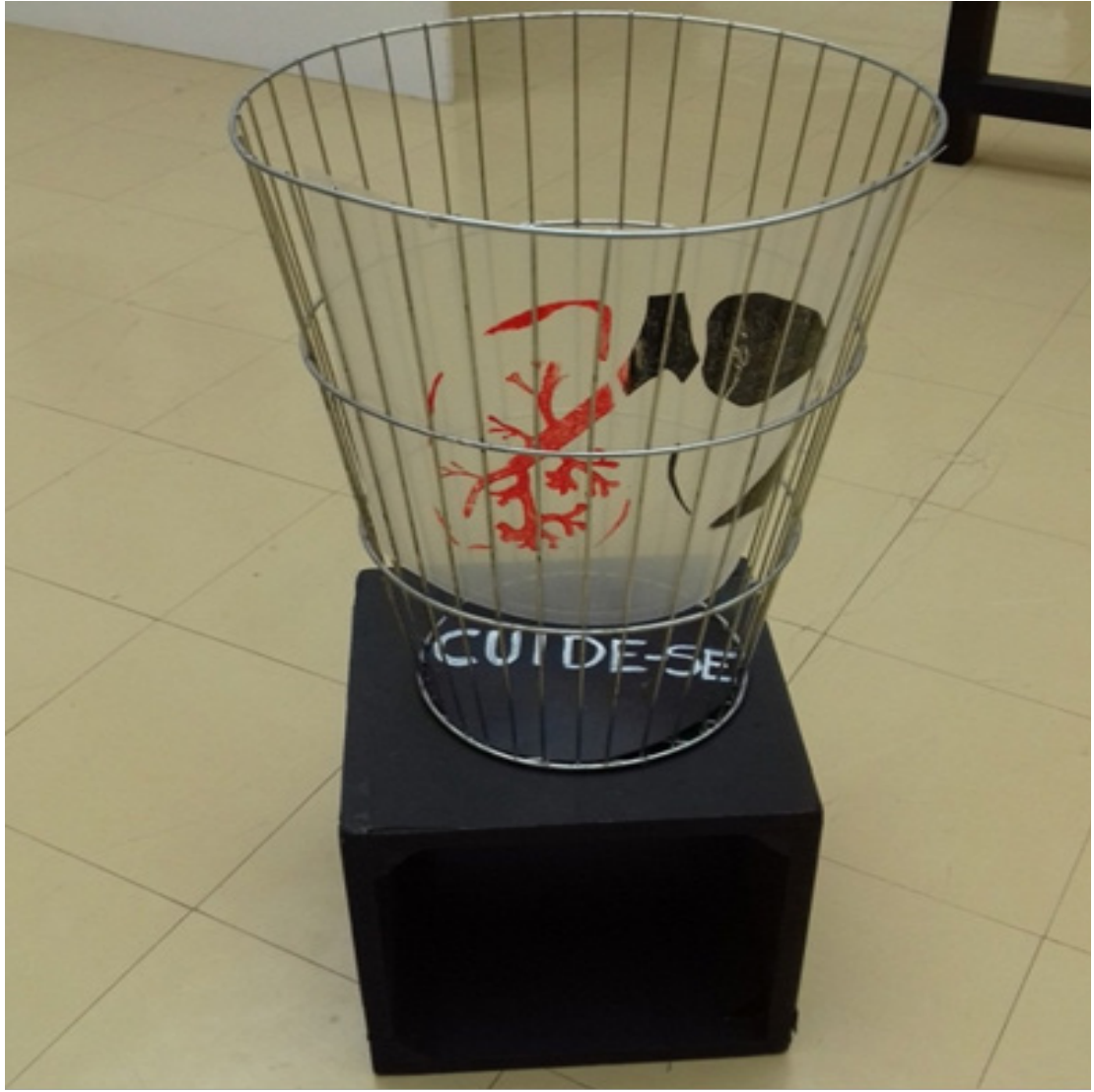

Fonte: SBEGHEN; SCORTEGANHA; ISER, 2016.

Fotografia 6

Conjunto de vidros de conserva que recebeu o título de Conserve a vida: doe sangue.

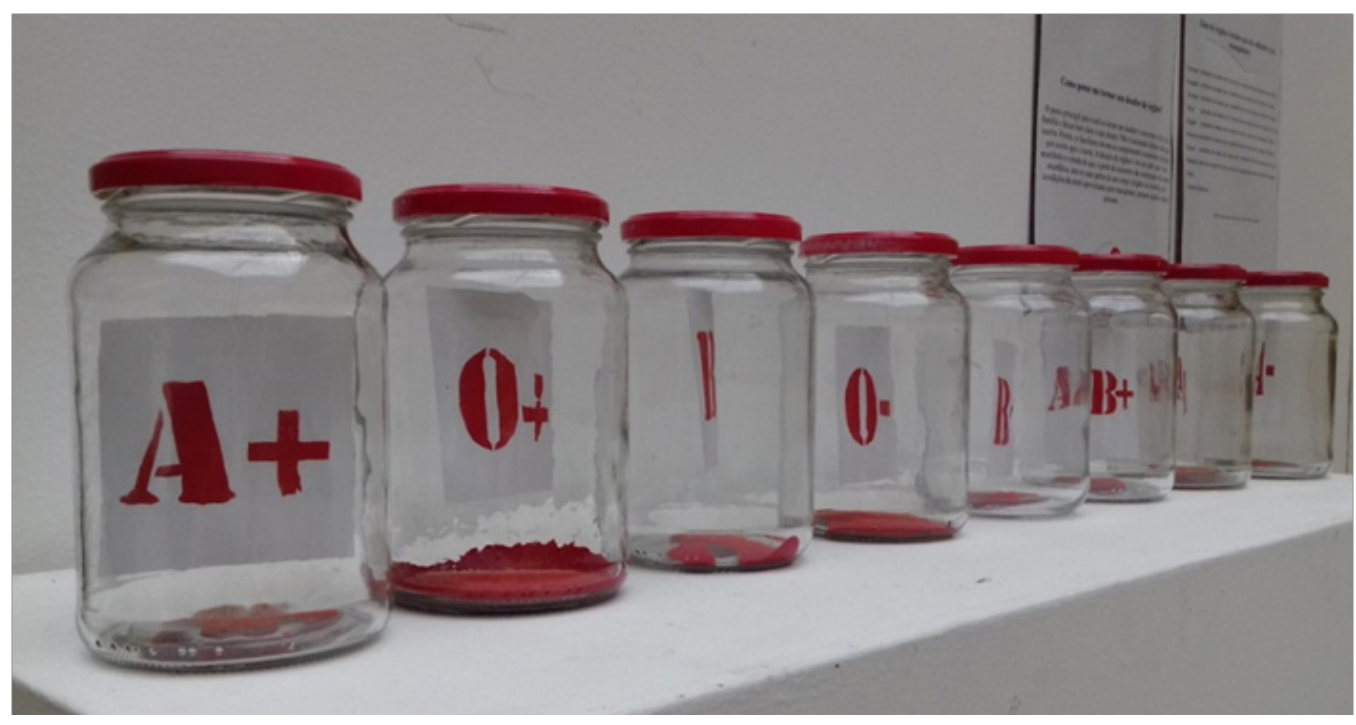

Fonte: SBEGHEN; SCORTEGANHA; ISER, 2016. 


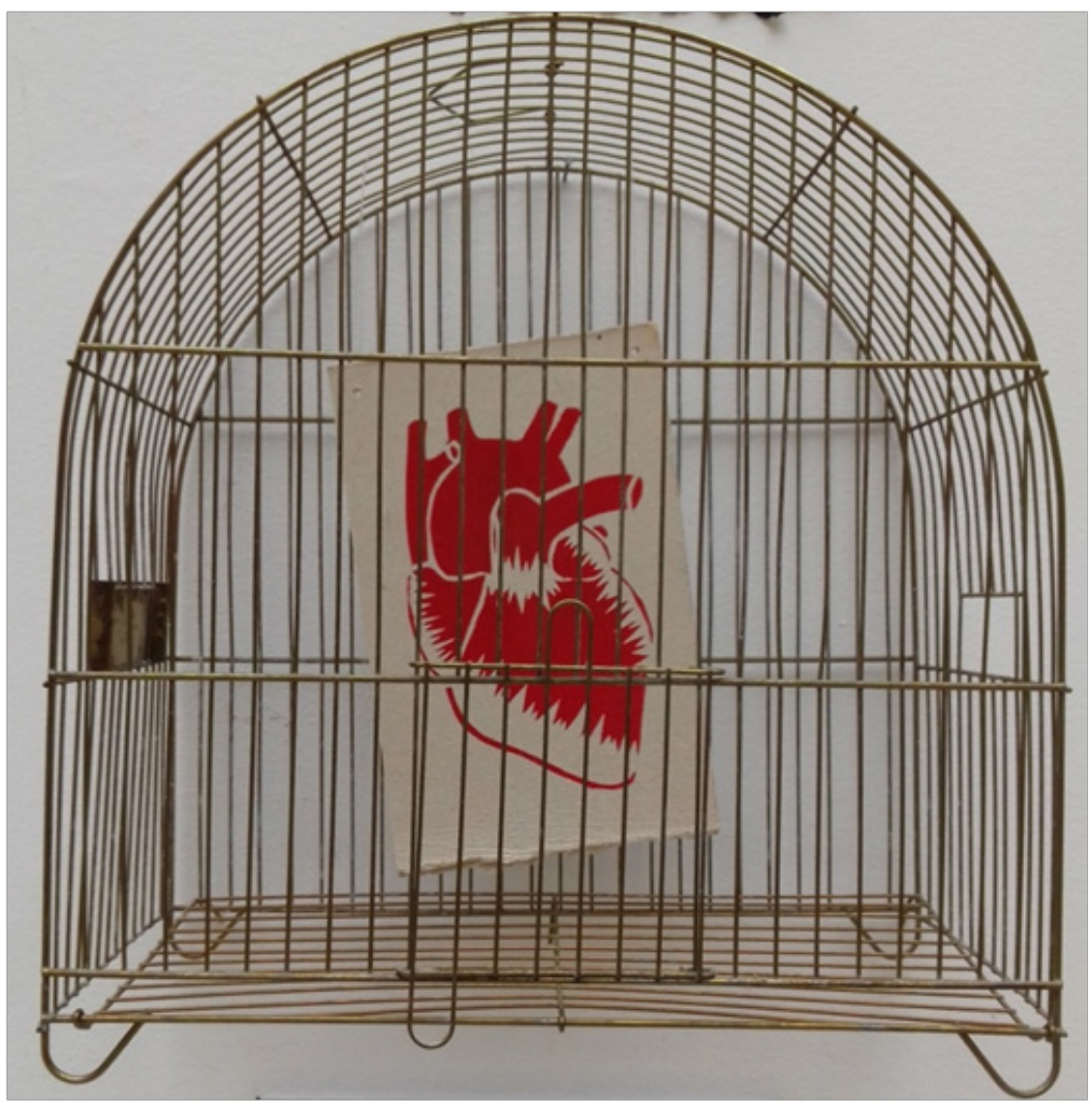

Fotografia 7

Representação de coração impressa pela técnica de estêncil sobre papel reciclado, dentro de gaiola, intitulado Liberte Vidas.

Fonte: SBEGHEN; SCORTEGANHA; ISER, 2016.

UM NOVO OLHAR SOBRE A EXPOSIÇÃO

"Olhar, contemplar, passa por momentos sutis: percebemos os objetos (ou paisagens), os interpretamos e classificamos num determinado contexto, para, quem sabe, por fim, recriarmos aquilo que vimos".(PATRíCIO, 2017).

Com o intuito de sensibilizar através da arte para a importância da doação de órgãos e tecidos, a exposição, por sua característica de instalação, convidou os participantes para a interação com os objetos de arte expostos, tornando essa experiência mais expressiva ao atribuírem títulos aos trabalhos que foram ressignificados com os novos olhares sobre 0 tema da exposição. 


\begin{abstract}
O olhar de cada um está impregnado com experiências anteriores, associações, lembranças, fantasias, interpretações, etc. O que se vê não é o dado real, mas aquilo que se consegue captar e interpretar acerca do visto, o que nos é significativo. Desse como, podemos lançar diferentes olhares e fazer uma pluralidade de leituras do mundo. (PILLAR, p. 13, 2009)
\end{abstract}

O manequim (Fotografia 2), que levava o nome da mostra e fez referência à doação de pele, recebeu o título de Órgão Doado é Órgão Aproveitado. Por conta desse trabalho, muitas dúvidas foram levantadas pelo grupo acerca da doação de pele. A equipe do CIHDOTT contribui com informações pertinentes às questões, relatando que a conservação da pele é feita no glicerol, que tem validade de até dois anos e que pessoas vivas também podem doar pele, pois a camada retirada é de apenas 1,5 milímetros de espessura e costuma ser retirada da barriga, costas e coxa. Se o doador for homem, a perna também pode ser usada. No caso de doações post-mortem, a pessoa deve ter sofrido morte encefálica ou parada cardiorrespiratória.

Radiografias de tecido ósseo (Fotografia 3) reutilizadas foram ressignificadas e ao serem retiradas partes dela, fizeram referência à doação desse tecido. Muitos no grupo não sabiam que existem bancos de ossos no Brasil, havendo, novamente, a fala dos participantes da CIHDOTT para elucidar dúvidas em relação à maneira de manter esse tecido em estoque. O trabalho com as radiografias recebeu o título de Na Transparência do Corpo, a Silhueta do Destino.

Bolsas de algodão (Fotografia 4), com identificação numérica, colocadas em cabides de metal, pertencentes ao antigo ambulatório central da UPF, receberam a interferência da impressão com xilogravuras e estêncis, representando alguns dos órgãos e tecidos que mais aparecem na lista de espera. Este trabalho foi chamado pelo grupo de Cabides de Vidas, por conta da forma como foi apresentado na exposição.

A representação de um pulmão pintado sobre papel vegetal "jogado" no lixo, com um aviso de cuide-se (Fotografia 5) fez os participantes repensarem até seus hábitos diários durante a roda de conversa. Alguns comentaram que ao recusarmos a doação de órgãos, de uma forma simbólica, estamos colocando no lixo aquilo que pode ser vital ou melhorar a qualidade de vida de outros.

Os vidros de conserva, com tinta na cor vermelha em seu interior e impressos de estêncil com informação dos grupos sanguíneos (Fotografia 6), chamou muito a atenção dos participantes da exposição, pois sua objetividade levou os participantes a discutirem sobre a queda do estoque dos bancos de sangue e a frequência em que eles mesmos vão doar sangue. E por fim, o estêncil de uma representação de um coração em vermelho "preso" em uma gaiola (Fotografia 7), levou os participantes a intitularem esse trabalho como Liberte Vidas. 
Assim, como afirma Ana Mae Barbosa, a arte é uma linguagem que estimula a sensibilidade no ser,

\begin{abstract}
A Arte, como uma linguagem aguçadora dos sentidos transmite significados que não podem ser transmitidos através de nenhum outro tipo de linguagem, tais como a discursiva e a científica [...]. Por meio da arte, é possível desenvolver a percepção e a imaginação, apreender a realidade do meio ambiente, desenvolver a capacidade crítica, permitindo ao indivíduo analisar a realidade percebida e desenvolver a criatividade de maneira a mudar a realidade que foi analisada. (BARBOSA, 2009, p. 21)
\end{abstract}

\title{
CONSIDERAÇÕES FINAIS
}

Observou-se que a exposição dos objetos de arte foi fundamental para promover a reflexão e a sensibilização decorrente da temática abordada na III Semana do Conhecimento. Percebeu-se na fala dos participantes as referências observadas na exposição e a contribuição das construções bi e tridimensionais para a memória visual daqueles que se permitiram vivenciar a discussão desse tema essencial para a saúde pública.

Depois de exposta durante o evento, a mostra permanece itinerante, participando da divulgação da Campanha Permanente de Doação de Órgãos e Tecidos do HSVP, na cidade de Passo Fundo e região.

\section{REFERÊNCIAS}

ABTO. Associação Brasileira de Transplante de Órgãos. Dados numéricos da doação de órgãos e transplantes realizados por estado e instituição no período: janeiro/setembro - Registro Brasileiro de Transplantes,v.22, n. 3, 2016. Disponível em: <http://www.abto.org.br/abtov03/Upload/file/ RBT/2016/RBT20163t-let.pdf>. Acessado em: 01 out. 2016.

BARBOSA, Ana Mae Tavares Bastos. Mediação cultural é social. In: BARBOSA, Ana Mae T. B.; COUTINHO, Rejane Galvão (Orgs.). Arte/Educação como mediação cultural e social. São Paulo: Ed. UNESP, 2009. p. 13-22.

KLEIN, Jacky; KLEIN, Suzy. O que é arte contemporânea? São Paulo: Claro Enigma, 2012.

MORAIS, Taise Ribeiro; MORAIS, Maricelma Ribeiro. Doação de órgãos: é preciso educar para avançar. Saúde em Debate, Rio de Janeiro, v. 36, n. 95, p. 633-639, out./dez. 2012. 
PATRÍCIO, Patrícia. A construção do olhar. (Reportagem). Itaú Cultural. Disponível em:<http://www.itaucultural.org.br/materiacontinuum/agosto2008-a-construcao-do-olhar/>. Acesso em: 08 mar. 2017.

PILLAR, Analice Dutra. Leitura e Releitura. In: .(Org.). A educação do olhar no ensino das artes. 5. ed. Porto Alegre: Mediação, 2009. p.1321.

STRICKLAND, Carol; BOSWELL, John. Arte comentada: da pré-história ao pós-moderno. 15 ed. Rio de Janeiro: Nova Fronteira,2014.

Data de recebimento: 30 de março de 2017.

Data de aceite para publicação: 17 de maio de 2017. 